\title{
In Vitro Adenosine Triphosphate-Based Chemotherapy Response Assay as a Predictor of Clinical Response to Fluorouracil-Based Adjuvant Chemotherapy in Stage II Colorectal Cancer
}

\author{
Hye Youn Kwon, MD' \\ Im-kyung Kim, MD2 \\ Jeonghyun Kang, MD2 \\ Seung-Kook Sohn, MD, PhD² \\ Kang Young Lee, $\mathrm{MD}, \mathrm{PhD}^{3}$
}

\begin{abstract}
${ }^{1}$ Department of Surgery, Sahmyook Medical Center, Seoul, ${ }^{2}$ Department of Surgery, Gangnam Severance Hospital, Yonsei University College of Medicine, Seoul, ${ }^{3}$ Department of Surgery, Severance Hospital, Yonsei University College of Medicine, Seoul, Korea
\end{abstract}

Correspondence: Kang Young Lee, MD, PhD Department of Surgery, Severance Hospital, Yonsei University College of Medicine, 50-1 Yonsei-ro, Seodaemun-gu, Seoul 03722, Korea

Tel: $82-2-2228-2096$

Fax: 82-2-313-8289

E-mail: kylee117@yuhs.ac

Received April 19, 2015

Accepted September 30, 2015

Published Online October 22, 2015

\begin{abstract}
Purpose
We evaluated the usefulness of the in vitro adenosine triphosphate-based chemotherapy response assay (ATP-CRA) for prediction of clinical response to fluorouracil-based adjuvant chemotherapy in stage II colorectal cancer.
\end{abstract}

\section{Materials and Methods}

Tumor specimens of 86 patients with pathologically confirmed stage II colorectal adenocarcinoma were tested for chemosensitivity to fluorouracil. Chemosensitivity was determined by cell death rate (CDR) of drug-exposed cells, calculated by comparing the intracellular ATP level with that of untreated controls.

\section{Results}

Among the 86 enrolled patients who underwent radical surgery followed by fluorouracilbased adjuvant chemotherapy, recurrence was found in 11 patients (12.7\%). The CDR $\geq 20 \%$ group was associated with better disease-free survival than the CDR $<20 \%$ group (89.4\% vs. $70.1 \%, p=0.027$ ). Multivariate analysis showed that CDR $<20 \%$ and T4 stage were poor prognostic factors for disease-free survival after fluorouracil-based adjuvant chemotherapy.

\section{Conclusion}

In stage II colorectal cancer, the in vitro ATP-CRA may be useful in identifying patients likely to benefit from fluorouracil-based adjuvant chemotherapy.

\section{Introduction}

Since the 1970s, a number of in vitro chemosensitivity assays have been developed for determining the sensitivity of cancer cells to various chemotherapeutic agents [1]. However, these tests are not commonly used in daily practice, primarily because of their low success rates in primary cell culture, poor correlation between assay results and clinical response, long turnaround time, and need for a relatively

\begin{abstract}
Key words
Colorectal neoplasms, Adjuvant chemotherapy, Antitumor drug screening assays
\end{abstract}

large amount of tissue [2-4]. The adenosine triphosphatebased chemotherapy response assay (ATP-CRA) was recently developed for evaluation of tumor cell viability by comparing intracellular ATP levels of drug-exposed cells with that of an untreated control. The ATP-CRA has some advantages over conventional chemosensitivity tests, including a short 7-day turnaround time and an ability to test cell viability in small amounts of tissue [5]. In addition, the clinical feasibility of this study has been validated in various cancers, including colorectal cancer [5-10]. 
Adjuvant chemotherapy can improve survival after curative resection of advanced colorectal cancer and has been widely accepted as a standard treatment in stage III colorectal cancer. However, the benefit of adjuvant chemotherapy in stage II colorectal cancer is still controversial [11,12]. ATPCRA has been used prediction of chemotherapy responsiveness based on the biological characteristics of the primary tumor. However, to the best of our knowledge, the ability of ATP-CRA to predict clinical response to adjuvant chemotherapy in stage II colorectal cancer has not yet been evaluated. The aim of this study was to evaluate the usefulness of the in vitro ATP-CRA as an indicator of clinical response to fluorouracil (5-FU)-based adjuvant chemotherapy in stage II colorectal cancer.

\section{Materials and Methods}

Clinical data and ATP-CRA results of consecutive patients who underwent radical resection for colorectal cancer from June 2004 to December 2008 were collected prospectively. All patients had histologically proven primary adenocarcinoma of the colon and rectum. Tumor tissue for the APT-CRA was obtained from the resected specimens in the operating room, and interpretable results were obtained for 366 patients. Among them, patients with distant metastases at preoperative staging, microscopic cancer invasion on the surgical margins (including radial resection margin), or any preoperative anti-cancer treatments (including preoperative radiotherapy), as wells as patients treated with adjuvant chemotherapy including oxaliplatin or irinotecan-based regimen were excluded.

The criteria for inclusion were stage II patients after radical resection, and patients who had undergone 5-FU-based adjuvant chemotherapy. Among the 366 patients, 86 patients were finally enrolled for the current analysis. Informed consent was obtained from all patients.

\section{ATP-CRA}

The technique of ATP-CRA was described in our previous report [8]. Briefly, fresh tumor tissue $\left(\geq 0.5 \mathrm{~cm}^{3}\right)$ obtained from surgical specimens in the operating theater were stored in Hank's balanced salt solution (Gibco BRL, Rockville, MD) and delivered to the laboratory. The tissue specimens were washed with $70 \%$ ethanol, quantified, and minced before incubation at $37^{\circ} \mathrm{C}$ for 12 to 16 hours with extracellular matrix-degrading enzymes. The cell suspensions were layered over a Ficoll density gradient medium $(1.077 \mathrm{~g} / \mathrm{mL})$ and centrifuged at $400 \times \mathrm{g}$ for 15 minutes. The viability of isolated cells was determined by trypan blue exclusion. Cells were diluted (2,000-20,000 viable cells / $100 \mu \mathrm{L})$, seeded into a 96-well ultra-low attachment microplate (Costar, Cambridge, $\mathrm{MA}$ ) with or without $10 \mu \mathrm{g} / \mathrm{mL} 5-\mathrm{FU}$, and incubated for 48 hours in a $\mathrm{CO}_{2}$ incubator. The concentration of $5-\mathrm{FU}$ was determined by a preliminary experiment, which showed a scattered distribution of cell death from each specimen at that concentration. To determine ATP concentration, luciferin and excess luciferase (Roche, Mannheim, Germany) were added to the cell lysate, and luciferase activity was measured using a Victor 3 multilabel counter (PerkinElmer, Boston, MA). The raw data were analyzed using Report Maker ver. 1.1 (ISU ABXIS, Seoul, Korea). Cell death rate was then calculated as follows: cell death rate $(\%)=[1-($ mean luminescence in treatment group/mean luminescence in untreated control group) $] \times 100$. The test was considered a failure if microbial contamination was detected, the number of cells was inadequate, or if the intra-assay mean coefficient of variation exceeded 30. If measured values in the untreated control group were lower than that of the positive control group (105 pg ATP), the specimen was considered to have low viability that was unacceptable for analysis.

\section{5-FU sensitivity}

Sensitivity to 5-FU was defined as $\geq 20 \%$ reduction of ATP in 5-FU-treated cells compared with untreated controls, and resistance to 5 -FU was defined as $<20 \%$ reduction in ATP. The sensitivity criterion of $20 \%$ was determined by the value which can most definitely discriminate the oncologic outcomes.

\section{Follow-up}

Patients were monitored at 3-month intervals for the first 2 years, 6-month intervals for the next 3 years, and yearly thereafter. Follow-up consisted of physical examination and measurement of serum carcinoembryonic antigen levels at every visit, yearly computed tomography scans of the chest and abdomen-pelvis in the first 5 years, and colonoscopy every 1 to 3 years. The median follow-up period was 50.0 months (range, 6 to 75 months).

\section{Statistical analysis}

All statistical analyses were performed using SPSS ver. 18.0 (SPSS Inc., Chicago, IL). Cell death rate was evaluated for its ability to predict recurrence, with the optimal cut-off value defined as the point on the receiver operating characteristic curve with the minimum distance between the $0 \%$ false-positive and $100 \%$ true-positive rates.

Categorical variables were analyzed using chi-square test 
Table 1. Clinicopathologic characteristics of patients

\begin{tabular}{|c|c|c|c|}
\hline Characteristic & 5-FU-sensitive $(n=72)$ & 5-FU-resistant $(\mathrm{n}=14)$ & p-value \\
\hline \multicolumn{4}{|l|}{ Sex } \\
\hline Male & $52(72.2)$ & $6(42.9)$ & 0.032 \\
\hline Female & $20(27.8)$ & $8(57.1)$ & \\
\hline \multicolumn{4}{|l|}{ Age (yr) } \\
\hline$<65$ & $45(62.5)$ & $10(71.4)$ & 0.524 \\
\hline$\geq 65$ & $27(37.5)$ & 4 (28.6) & \\
\hline \multicolumn{4}{|l|}{ Tumor location } \\
\hline Colon & $44(61.1)$ & $9(64.3)$ & 0.820 \\
\hline Rectum & $28(38.9)$ & $5(35.7)$ & \\
\hline \multicolumn{4}{|l|}{ Histologic grade ${ }^{a}$} \\
\hline G1/G2 & $63(87.5)$ & $12(85.7)$ & $0.850^{\mathrm{b})}$ \\
\hline G3/etc. & $9(12.5)$ & $2(14.3)$ & \\
\hline \multicolumn{4}{|l|}{ Pathologic T stage } \\
\hline T3 & $69(95.8)$ & $13(92.9)$ & $0.630^{\mathrm{b})}$ \\
\hline $\mathrm{T} 4$ & $3(4.2)$ & $1(7.1)$ & \\
\hline \multicolumn{4}{|l|}{ Retrieved LNs } \\
\hline$<12$ & $11(15.3)$ & $2(14.3)$ & 0.920 \\
\hline$\geq 12$ & $61(84.7)$ & $12(85.7)$ & \\
\hline \multicolumn{4}{|l|}{ LVI } \\
\hline No & $68(94.4)$ & $1(7.1)$ & $0.821^{\mathrm{b})}$ \\
\hline Yes & $4(5.7)$ & $2(6.1)$ & \\
\hline \multicolumn{4}{|l|}{ CDR $(\%)$} \\
\hline Median (range) & $37.6(20.2-72.3)$ & $14.0(0-19.6)$ & $<0.001$ \\
\hline \multicolumn{4}{|l|}{ MSI status } \\
\hline MSS & $21(2.8)$ & $8(57.1)$ & $0.118^{\mathrm{b})}$ \\
\hline MSI-H & $2(29.2)$ & 0 & \\
\hline No data & $49(68.1)$ & $6(42.9)$ & \\
\hline \multicolumn{4}{|l|}{ Recurrence } \\
\hline Overall & $7(9.7)$ & $4(28.6)$ & $0.053^{\mathrm{b})}$ \\
\hline \multicolumn{4}{|l|}{ Systemic } \\
\hline Liver & $3(4.2)$ & $1(7.1)$ & $0.516^{\mathrm{b})}$ \\
\hline Lung & $2(2.8)$ & $2(14.3)$ & $0.122^{b)}$ \\
\hline Peritoneum & $1(1.4)$ & 0 & $>0.999^{b)}$ \\
\hline Systemic LNs & $1(1.4)$ & 0 & $>0.999$ \\
\hline Combined & 0 & $1(7.1)$ & 0.163 \\
\hline
\end{tabular}

Values are presented as number (\%) unless otherwise indicated. 5-FU, fluorouracil; LN, lymph nodes; LVI, lymphovascular invasion; CDR, cell death rate; MSI, microsatellite instability; MSS, microsatellite stable; MSI-H, high-frequency microsatellite

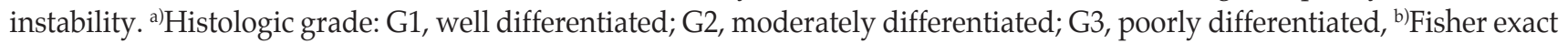
test.

or Fisher exact test, and continuous variables were analyzed using Student's t test. Disease-free survival (DFS) was measured from the date of curative surgery to the date of recurrence or death before relapse. Univariate and multivariate Cox regression analyses were performed; $\mathrm{p}<0.05$ was considered significant.

\section{Results}

Of the 86 enrolled patients, 72 patients $(83.7 \%)$ were categorized as 5-FU-sensitive, and 14 patients (16.3\%) as 5-FU-resistant. Other than sex, clinicopathologic parameters did not differ between the two patient groups. The rate of recurrence was higher in the 5-FU-resistant group, but with- 
Table 2. Clinicopathological comparison between right and left colon

\begin{tabular}{|c|c|c|c|}
\hline Characteristic & Right colon $(n=26)$ & Left colon $(n=60)$ & p-value \\
\hline \multicolumn{4}{|l|}{ Sex } \\
\hline Male & $18(69.2)$ & $40(66.7)$ & 0.816 \\
\hline Female & $8(30.8)$ & $20(33.3)$ & \\
\hline \multicolumn{4}{|l|}{ Age (yr) } \\
\hline$<65$ & $14(53.8)$ & $41(68.3)$ & 0.199 \\
\hline$\geq 65$ & $12(46.2)$ & $19(31.7)$ & \\
\hline \multicolumn{4}{|l|}{ Obstruction } \\
\hline Yes & $1(3.8)$ & $3(5.0)$ & $\left.>0.999^{a}\right)$ \\
\hline No & $25(96.2)$ & $57(95.0)$ & \\
\hline \multicolumn{4}{|l|}{ Perforation } \\
\hline Yes & 0 & $1(1.7)$ & $>0.999^{a)}$ \\
\hline No & $26(100)$ & $59(98.3)$ & \\
\hline \multicolumn{4}{|c|}{ Histologic grade ${ }^{b}$} \\
\hline $\mathrm{G} 1 / \mathrm{G} 2$ & $22(84.6)$ & $53(88.3)$ & $0.728^{a)}$ \\
\hline G3/ etc. & $4(15.4)$ & 7 (11.7) & \\
\hline \multicolumn{4}{|c|}{ Pathologic T stage } \\
\hline $\mathrm{T} 3$ & $25(96.2)$ & $57(95.0)$ & $\left.>0.999^{a}\right)$ \\
\hline $\mathrm{T} 4$ & $1(3.8)$ & $3(5.0)$ & \\
\hline \multicolumn{4}{|l|}{ Retrieved LNs } \\
\hline$<12$ & $1(3.8)$ & $12(20.0)$ & $0.097^{\mathrm{a})}$ \\
\hline$\geq 12$ & $25(96.2)$ & $48(80.0)$ & \\
\hline \multicolumn{4}{|l|}{ LVI } \\
\hline No & $24(92.3)$ & $57(95.0)$ & $0.636^{a)}$ \\
\hline Yes & $2(7.7)$ & $3(5.0)$ & \\
\hline \multicolumn{4}{|l|}{ MSI data } \\
\hline Not available & $16(61.5)$ & $39(65.0)$ & \\
\hline Available & $10(38.5)$ & $21(35.0)$ & $\left.>0.999^{a}\right)$ \\
\hline MSS & $9(90.0)$ & $20(95.2)$ & \\
\hline MSI-H & $1(10.0)$ & $1(4.8)$ & \\
\hline \multicolumn{4}{|l|}{ Chemosensitivity } \\
\hline Sensitive & $21(80.8)$ & $51(85.0)$ & $0.752^{a)}$ \\
\hline Resistant & $5(19.2)$ & $9(15.0)$ & \\
\hline
\end{tabular}

Values are presented as number (\%). LN, lymph nodes; LVI, lymphovascular invasion; MSI, microsatellite instability; MSS, microsatellite stable; MSI-H, high-frequency microsatellite instability. ${ }^{a}$ Fisher exact test, ${ }^{\text {b) }}$ Histologic grade: G1, well differentiated; G2, moderately differentiated; G3, poorly differentiated.

out significance ( $\mathrm{p}=0.053)$ (Table 1$)$. According to the tumor location, there was no difference of clinicopathologic parameters in our cohort (Table 2).

Survival analyses according to chemosensitivity to 5-FU are shown in Fig. 1. The median DFS was 48.0 months (range, 6 to 75 months). The 5 -year DFS rate was $89.4 \%$ in the 5-FUsensitive group and $70.1 \%$ in the 5 -FU-resistant group $(\mathrm{p}=0.027)$. According to the database, the DFS of stage II patients who did not undergo adjuvant chemotherapy $(n=36)$ during the study periods were calculated for comparison (5-year DFS, 78.7\%) (Fig. 1).

Considering high-risk stage II patients $(n=33)$ with patho- logic T4, poor histologic grade, presence of lymphovascular invasion, obstruction or perforation and retrieved lymph nodes lower than 12 , the 5-year DFS rate was significantly better in the 5-FU-sensitive group ( $\mathrm{n}=26)$ compared to the 5-FU-resistant group (5-year DFS, $87.5 \%$ vs. $35.7 \%$; $\mathrm{p}=0.001$ ), but there was no significant difference in DFS of low-risk stage II patients between the two groups (Fig. 2A and B).

Univariate analysis showed that pathologic T4 stage and 5-FU resistance were significant factors predicting DFS (pathologic T3 vs. T4, 89.5\% vs. $25.0 \%$; p $<0.001$ and 5-FUsensitive vs. 5 -FU-resistant, $89.4 \%$ vs. $70.1 \%$; $\mathrm{p}=0.027$, respectively). Multivariate analysis confirmed the predictive power 


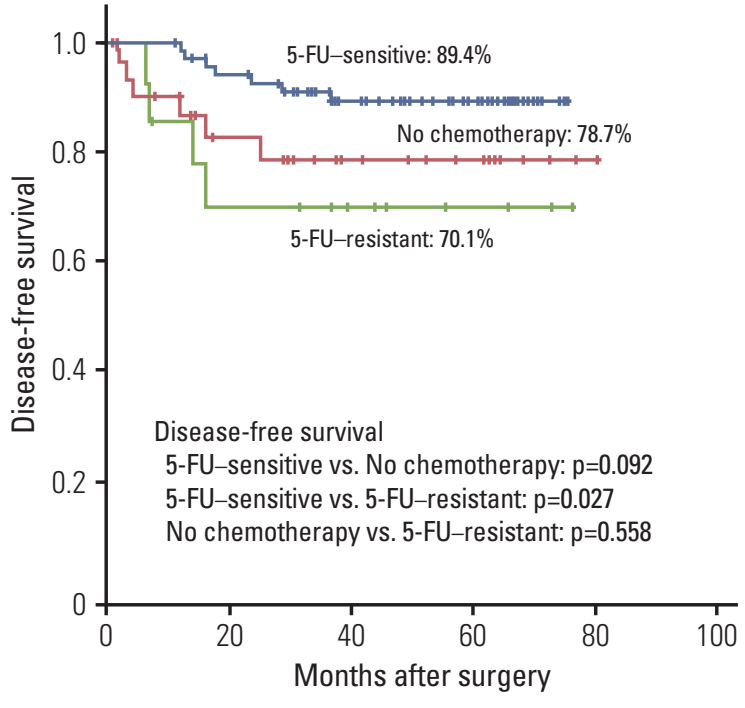

Fig. 1. Disease-free survival analyses according to the chemosensitivity to fluorouracil (5-FU). The 5-year disease-free survival was significantly longer in 5-FU-sensitive patients than in 5-FU-resistant patients $(89.4 \%$ vs. $70.1 \%, p=0.027)$. No chemotherapy group who did not receive adjuvant chemotherapy during the study periods was extracted from our database. of these factors (pathologic T4: hazard ratio [HR], 13.7; confidence interval $[\mathrm{CI}], 3.3$ to $56.2 ; \mathrm{p}<0.001 ; 5-\mathrm{FU}$ resistant: $\mathrm{HR}$, 4.7; CI, 1.3 to 17.3; $\mathrm{p}=0.018$ ) (Table 3).

\section{Discussion}

In this study, the 5-year DFS rate in patients with stage II colorectal cancer was significantly higher among those whose tumor cells were shown to be 5-FU-sensitive by the in vitro ATP-CRA test. These results indicate the promise of tailored adjuvant chemotherapy in stage II colorectal cancer based on ATP-CRA. The survival benefit of adjuvant chemotherapy following radical resection of the tumor is limited [11,12]. Identification of patients who are sensitive to specific chemotherapy drugs may facilitate a more tailored approach based on prognostic and predictive factors, which may increase the survival benefit of chemotherapy while minimizing its side effects. The use of adjuvant therapy in patients with poor prognosis has been widely accepted as standard treatment [13]. Bowel obstruction at presentation, perforation of the colon at the tumor site, poor histologic grade, and peritumoral lymphovascular involvement have been identified as poor prognostic factors in node-negative colorectal cancer $[14,15]$. In patients with these prognostic
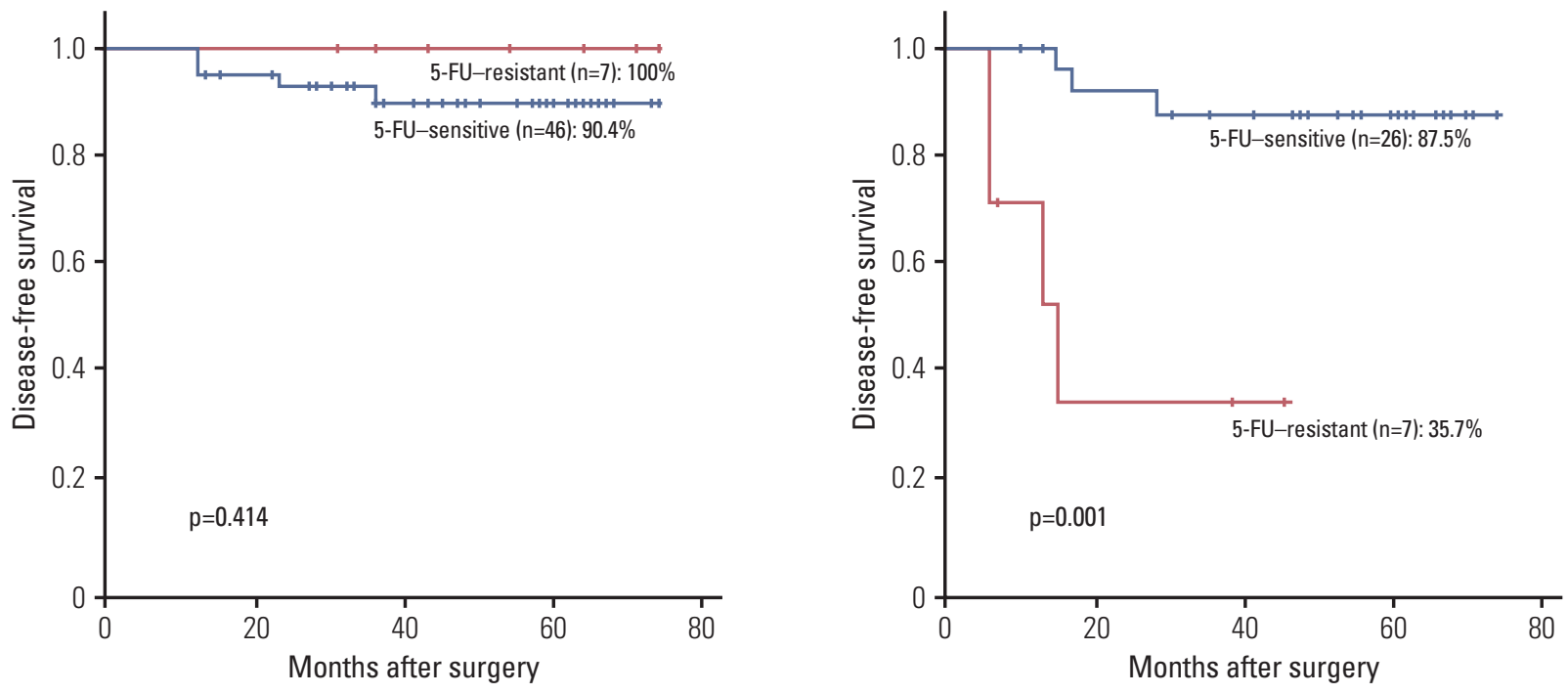

Fig. 2. Disease-free survival analyses in low-risk and in high-risk stage II patients. (A) 5-Year disease-free survival rate in the low-risk stage II patients according to the chemosensitivity to fluorouracil (5-FU). (B) 5-Year disease-free survival rate in the high-risk stage II patients according to the chemosensitivity to 5-FU. 
Table 3. Univariate and multivariate analysis of factors predicting DFS

\begin{tabular}{|c|c|c|c|c|c|}
\hline \multirow{2}{*}{ Characteristic } & \multirow{2}{*}{ No. } & \multicolumn{2}{|c|}{ Univariate analysis } & \multicolumn{2}{|c|}{ Multivariate analysis } \\
\hline & & 5-Yr DFS (\%) & p-value & HR $(95 \%$ CI) & p-value \\
\hline \multicolumn{6}{|l|}{ Sex } \\
\hline Male & 58 & 88.8 & 0.319 & - & - \\
\hline Female & 28 & 80.9 & & - & \\
\hline \multicolumn{6}{|l|}{ Age (yr) } \\
\hline$<65$ & 55 & 83.4 & 0.220 & - & - \\
\hline$\geq 65$ & 31 & 91.6 & & - & \\
\hline \multicolumn{6}{|l|}{ Tumor location } \\
\hline Colon & 53 & 90.3 & 0.194 & - & - \\
\hline Rectum & 33 & 79.3 & & - & \\
\hline \multicolumn{6}{|l|}{ Obstruction } \\
\hline Yes & 4 & 66.7 & 0.332 & - & - \\
\hline No & 82 & 87.1 & & - & \\
\hline \multicolumn{6}{|c|}{ Histologic grade $\left.{ }^{a}\right)$} \\
\hline G1/G2 & 75 & 87.1 & 0.488 & - & - \\
\hline G3/etc. & 11 & 80.8 & & - & \\
\hline \multicolumn{6}{|c|}{ Pathologic T stage } \\
\hline T3 & 82 & 89.5 & $<0.001$ & 1 & $<0.001$ \\
\hline $\mathrm{T} 4$ & 4 & 25.0 & & $13.7(3.3-56.2)$ & \\
\hline \multicolumn{6}{|l|}{ Retrieved LNs } \\
\hline$<12$ & 13 & 83.3 & 0.771 & - & - \\
\hline$\geq 12$ & 73 & 86.9 & & - & \\
\hline \multicolumn{6}{|l|}{ LVI } \\
\hline No & 81 & 86.8 & 0.709 & - & - \\
\hline Yes & 5 & 80.0 & & - & \\
\hline \multicolumn{6}{|l|}{ MSI status } \\
\hline MSS & 29 & 83.8 & 0.845 & - & - \\
\hline MSI-H & 2 & 100.0 & & - & \\
\hline No data & 55 & 86.6 & & - & \\
\hline \multicolumn{6}{|c|}{ Chemosensitivity } \\
\hline Sensitive & 72 & 89.4 & 0.027 & 1 & \\
\hline Resistant & 14 & 70.1 & & $4.7(1.3-17.3)$ & 0.018 \\
\hline
\end{tabular}

DFS, disease-free survival; HR, hazard ratio; CI, confidence interval; LN, lymph nodes; LVI, lymphovascular invasion; MSI,

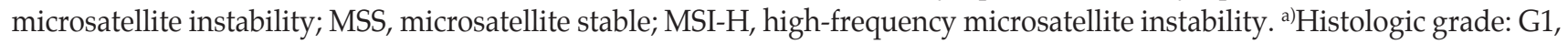
well differentiated; G2, moderately differentiated; G3, poorly differentiated.

factors, adjuvant chemotherapy has been shown to decrease the recurrence rate, resulting in a $4 \%$ survival benefit [16]. Predictive markers for chemoresponse have also been evaluated for tailored adjuvant chemotherapy in stage II colorectal cancer. Most of these studies focused on molecular characteristics of the primary tumor such as microsatellite instability (MSI), 18q deletions, mutations in KRAS and TP53, and thymidylate synthase gene expression [17-19]. In addition, use of gene expression arrays has been attempted for prediction of drug response based on a specific gene signature $[20,21]$. However, we are far from being able to accu- rately predict drug response by molecular characterization of the primary tumor. Alternatively, the in vitro chemosensitivity assay evaluates the response of cultured cancer cells to chemotherapeutic agents. In the current study we attempted to identify patients who are likely to benefit from adjuvant chemotherapy, regardless of their risk factors, by means of ATP-CRA. Our results showed that ATP-CRA could predict the efficacy of 5-FU-based adjuvant chemotherapy in stage II colorectal cancer.

In vitro ATP-CRA has been used in prediction of chemoresponse in several cancers. For example, in a study of metasta- 
tic breast cancer, mean cell death rate was lower in nonresponders than in responders to docetaxel alone or doxorubicin plus paclitaxel ( $\mathrm{p}=0.012)$; in vitro ATP-CRA was shown to have high specificity and positive predictive value for predicting clinical response in these patients [22]. The benefit of ATP-CRA-guided chemotherapy was also demonstrated in patients with gastric cancer. Adjuvant chemotherapy after curative resection increased time to relapse in patients determined to have chemotherapy-sensitive gastric cancer by ATP-CRA (relapse not reached in the sensitive group vs. 24.8 months in the resistant group, $\mathrm{p}=0$.043) [23]. A prospective study of colorectal cancer demonstrated that ATP-CRAguided chemotherapy increased resectability in patients with unresectable liver metastasis, compared with conventional chemotherapy (35.5\% vs. $12.5 \%, \mathrm{p}=0.032)$ [9].

In the current study, we evaluated the efficacy of in vitro ATP-CRA to identify patients with stage II colorectal cancer who are likely to benefit from adjuvant chemotherapy. To aid in the interpretation of results, all patients were treated with 5-FU-based chemotherapy only (no other adjuvant therapy, including radiotherapy) after curative resection of the primary tumor. In patients with tumors predicted to be sensitive to 5-FU, chemotherapy increased DFS. The results of this study suggest that in vitro ATP-CRA can predict the benefits of adjuvant chemotherapy in patients with stage II colorectal cancer.

MSI is a crucial mechanism of chemo-resistance to 5-FU, which has been well demonstrated in in-vitro and in-vivo studies $[24,25]$. Because of the loss of DNA damage sensor function in mismatch repair-defective cells, the lack of proper signaling for apoptosis induction occurs and develops resistance to 5-FU. In this study, high-frequency microsatellite instability (MSI-H) was detected in only two patients who were categorized as the 5-FU-sensitive group, based on in vitro ATP-CRA, and their survival was excellent without recurrence. For this reason, it is hard to find any clue regarding the relationship between MSI-H and ATP-CRA assay. It will be a valuable next step in clarifying the relationship between molecular biological characteristics and chemosensitivity assay.

A limitation of this study was the threshold value of $20 \%$ cell death rate for defining chemotherapy-sensitive and -resistant groups. Previous studies have reported various threshold values for cell death rate, ranging from 30\% to $50 \%$. This discrepancy suggests the difficulty of the clinical application. Therefore, our result should be confirmed in independent patient cohorts.

\section{Conclusion}

In conclusion, in vitro ATP-CRA may be a useful assay for identifying patients who might benefit from 5-FU-based adjuvant chemotherapy in stage II colorectal cancer.

\section{Conflicts of Interest}

Conflict of interest relevant to this article was not reported.

\section{References}

1. Hamburger AW, Salmon SE. Primary bioassay of human tumor stem cells. Science. 1977;197:461-3.

2. Rozencweig M, Hofmann V, Sanders C, Rombaut W, Fruh U, Martz G. In vitro growth of human malignancies in a cloning assay. Recent Results Cancer Res. 1984;94:1-7.

3. Yamaue H, Tanimura H, Tsunoda T, Tani M, Iwahashi M, Noguchi $\mathrm{K}$, et al. Chemosensitivity testing with highly purified fresh human tumour cells with the MTT colorimetric assay. Eur J Cancer. 1991;27:1258-63.

4. Vescio RA, Redfern CH, Nelson TJ, Ugoretz S, Stern PH, Hoffman RM. In vivo-like drug responses of human tumors growing in three-dimensional gel-supported primary culture. Proc Natl Acad Sci U S A. 1987;84:5029-33.

5. Kang SM, Park MS, Chang J, Kim SK, Kim H, Shin DH, et al. A feasibility study of adenosine triphosphate-based chemotherapy response assay (ATP-CRA) as a chemosensitivity test for lung cancer. Cancer Res Treat. 2005;37:223-7.

6. Cree IA, Kurbacher CM, Untch M, Sutherland LA, Hunter EM, Subedi AM, et al. Correlation of the clinical response to chemotherapy in breast cancer with ex vivo chemosensitivity. Anticancer Drugs. 1996;7:630-5.

7. Konecny G, Crohns C, Pegram M, Felber M, Lude S, Kurbacher $C$, et al. Correlation of drug response with the ATP tumorchemosensitivity assay in primary FIGO stage III ovarian cancer. Gynecol Oncol. 2000;77:258-63.

8. Huh JW, Park YA, Lee KY, Sohn SK. Heterogeneity of adenosine triphosphate-based chemotherapy response assay in colorectal cancer: secondary publication. Yonsei Med J. 2009;50: 697-703.

9. Hur H, Kim NK, Kim HG, Min BS, Lee KY, Shin SJ, et al. Adenosine triphosphate-based chemotherapy response assayguided chemotherapy in unresectable colorectal liver metas- 
tasis. Br J Cancer. 2012;106:53-60.

10. Park S, Woo Y, Kim H, Lee YC, Choi S, Hyung WJ, et al. In vitro adenosine triphosphate based chemotherapy response assay in gastric cancer. J Gastric Cancer. 2010;10:155-61.

11. Benson AB 3rd, Schrag D, Somerfield MR, Cohen AM, Figueredo AT, Flynn PJ, et al. American Society of Clinical Oncology recommendations on adjuvant chemotherapy for stage II colon cancer. J Clin Oncol. 2004;22:3408-19.

12. Schippinger W, Samonigg H, Schaberl-Moser R, Greil R, Thodtmann R, Tschmelitsch J, et al. A prospective randomised phase III trial of adjuvant chemotherapy with 5-fluorouracil and leucovorin in patients with stage II colon cancer. Br J Cancer. 2007;97:1021-7.

13. Compton CC, Fielding LP, Burgart LJ, Conley B, Cooper HS, Hamilton SR, et al. Prognostic factors in colorectal cancer. College of American Pathologists Consensus Statement 1999. Arch Pathol Lab Med. 2000;124:979-94.

14. Andre T, Boni C, Navarro M, Tabernero J, Hickish T, Topham $\mathrm{C}$, et al. Improved overall survival with oxaliplatin, fluorouracil, and leucovorin as adjuvant treatment in stage II or III colon cancer in the MOSAIC trial. J Clin Oncol. 2009;27: 3109-16.

15. Quasar Collaborative Group, Gray R, Barnwell J, McConkey C, Hills RK, Williams NS, et al. Adjuvant chemotherapy versus observation in patients with colorectal cancer: a randomised study. Lancet. 2007;370:2020-9.

16. Gill S, Loprinzi CL, Sargent DJ, Thome SD, Alberts SR, Haller DG, et al. Pooled analysis of fluorouracil-based adjuvant therapy for stage II and III colon cancer: who benefits and by how much? J Clin Oncol. 2004;22:1797-806.

17. Markowitz SD, Bertagnolli MM. Molecular origins of cancer: molecular basis of colorectal cancer. N Engl J Med. 2009;361: 2449-60.

18. Bertagnolli MM, Redston M, Compton CC, Niedzwiecki D, Mayer RJ, Goldberg RM, et al. Microsatellite instability and loss of heterozygosity at chromosomal location 18q: prospective evaluation of biomarkers for stages II and III colon cancer: a study of CALGB 9581 and 89803. J Clin Oncol. 2011;29: 3153-62.

19. Roth AD, Tejpar S, Delorenzi M, Yan P, Fiocca R, Klingbiel D, et al. Prognostic role of KRAS and BRAF in stage II and III resected colon cancer: results of the translational study on the PETACC-3, EORTC 40993, SAKK 60-00 trial. J Clin Oncol. 2010;28:466-74.

20. Salazar R, Roepman P, Capella G, Moreno V, Simon I, Dreezen $\mathrm{C}$, et al. Gene expression signature to improve prognosis prediction of stage II and III colorectal cancer. J Clin Oncol. 2011; 29:17-24.

21. Maak M, Simon I, Nitsche U, Roepman P, Snel M, Glas AM, et al. Independent validation of a prognostic genomic signature (ColoPrint) for patients with stage II colon cancer. Ann Surg. 2013;257:1053-8.

22. Kim HA, Yom CK, Moon BI, Choe KJ, Sung SH, Han WS, et al. The use of an in vitro adenosine triphosphate-based chemotherapy response assay to predict chemotherapeutic response in breast cancer. Breast. 2008;17:19-26.

23. Lee JH, Kim MC, Oh SY, Kwon HC, Kim SH, Kwon KA, et al. Predictive value of in vitro adenosine triphosphate-based chemotherapy response assay in advanced gastric cancer patients who received oral 5-Fluorouracil after curative resection. Cancer Res Treat. 2011;43:117-23.

24. Meyers M, Wagner MW, Hwang HS, Kinsella TJ, Boothman DA. Role of the hMLH1 DNA mismatch repair protein in fluoropyrimidine-mediated cell death and cell cycle responses. Cancer Res. 2001;61:5193-201.

25. Ribic CM, Sargent DJ, Moore MJ, Thibodeau SN, French AJ, Goldberg RM, et al. Tumor microsatellite-instability status as a predictor of benefit from fluorouracil-based adjuvant chemotherapy for colon cancer. N Engl J Med. 2003;349: 247-57. 